\title{
The socioeconomic correlates of substance use among male adults in Northeast India
}

\author{
Nandita Saikia ${ }^{\mathrm{a}, \mathrm{b}, *}$, Benjamin Debbarma ${ }^{\mathrm{b}}$ \\ ${ }^{a}$ International Institute for Applied Systems Analysis, Laxenburg, Austria \\ ${ }^{\mathrm{b}}$ Centre for the Study of Regional Development, School of Social Sciences, Jawaharlal Nehru University, New Delhi, India
}

\section{A R T I C L E I N F O}

\section{Keywords:}

Substance consumption

Socioeconomic correlates

Male adults

Northeast India

Scheduled tribes

\begin{abstract}
A B S T R A C T
Background: Substance use - defined by the consumption of alcohol, smoking, and smokeless tobacco - has been identified as a serious health hazard in India. Understanding the socioeconomic correlates of substance use in Northeast India (NEI) will provide crucial input for public health policies in this region.

Objectives: To examine the socioeconomic correlates of substance consumption among male adults of NEI. Data and methods: We analyzed nationally representative data from the National Family Health Survey (NFHS-4) 2015-2016. We examined the prevalence and frequency of smoking, using smokeless tobacco products, alcohol consumption, and other substance use among 14,555 men in the 15 to 54-year age group. We carried out binary logistic regressions to investigate the socioeconomic correlates of substance use among male adults in NEI.

Results: Substance use was significantly higher among the male adults of NEI than among those from elsewhere in the country (any substance i.e. smoking, smokeless tobacco and alcohol use in India: 50.03\% vs. NEI: 70.83\%). The frequency of smoking and alcohol consumption is also higher in NEI compared to the rest of the country. In total, there are about 10.2 million substance users, of which 6.7 million are from the state of Assam. About $44.38 \%$ of adolescents (aged between 15 and 19) use at least one type of substance. Substance use plateaus in the 25 to 49 age group before beginning to decline among users aged between 50 and 54 years. The likelihood of substance use goes down with increasing education and wealth in NEI. Among social groups, Scheduled Tribe adults have the highest likelihood of using any substance.

Conclusion: The intensity of substance consumption in NEI is very high. These unhealthy behaviors are more prevalent among socioeconomically disadvantaged populations. This calls for intensive research to better understand the dynamics of substance availability and use in NEI. Furthermore, strong policy measures are needed to reduce substance use among vulnerable groups.
\end{abstract}

\section{Introduction}

Substance use refers to the consumption of any psychoactive substance or drug, including both legal and illicit drugs, other than those indicated for medical use. Previous research has recognized substance use as an important factor leading to premature death and disease in the world. $^{1,2,3}$ Substance use can have negative consequences on the economy, productivity, and social well-being of communities. A recent cross-country study showed that $4 \cdot 2 \%$ of all disability-adjusted life years (DALYs) were attributable to alcohol use, and 1.3\% of all DALYs were attributable to drug use as a risk factor (GBD 2016 Alcohol and Drug Use Collaborators 2018). In India, it is found that nearly 4.52 trillion cigarettes and 40.3 trillion bidis were produced between 1910 and 2010, which are estimated to be responsible for nearly 100 million premature deaths (in which bidis contributed 77 million deaths) in adult men of $\geq 35$ years. ${ }^{4}$ Smoking (either bidi or cigarettes) causes half the male tuberculosis deaths in India, and a quarter of all male deaths in middle age. ${ }^{5}$ Smoking and chewing tobacco increase morbidity both among adults and the elderly.,7

Although there is great variation in substance use across different regions of India, ${ }^{8}$ limited efforts have been made to understand the prevalence and determinants of substance use at the regional level. In particular, there is a dearth of research on substance consumption in Northeast India (NEI). Various small-scale studies conducted in NEI demonstrated that substance use is high in this part of the country. ${ }^{9,10}$ It is found that found that the use of illicit drugs (like opium, heroin, proxyvan, etc.) has increased considerably in many parts of Northeast India. Using primary data in Assam and Meghalaya, this study found a

\footnotetext{
* Corresponding author. International Institute for Applied Systems Analysis, Laxenburg, Austria.

E-mail addresses: nanditasts@gmail.com, nanditasaikia@mail.jnu.ac.in (N. Saikia).
} 
higher prevalence of tobacco, alcohol, and opium in their study area. Using data from two large, nationally representative surveys, Ladusingh et al. ${ }^{11}$ found that the levels of any tobacco use in NEI have remained persistently high at above 50\% during 2009-2010 to 2012-2013. This study shows that tobacco consumption status of parents is highly and positively associated with the tobacco consumption status of youths in NEI. ${ }^{11}$

Data from two rounds of Global Adult Tobacco Survey (2009-2010 and 2016-2017) also show that substance consumption is considerably higher in NEI than in the rest of India. ${ }^{12,13}$ Yet, to our knowledge, no previous study has investigated substance use patterns and their correlates in NEI. In this study, we analyzed the prevalence, magnitude, and frequency of substance use in NEI. We also examined the socioeconomic correlates of substance use among adults aged 15-54 years of age in NEI. By doing so, we investigated both the absolute and relative burden of substance users and identified the most vulnerable population subgroups in need of specific interventions to reduce substance use in the region.

\section{Data}

We used recently released data from the fourth round of the National Family Health Survey 2015-2016 (hereafter referred to as NFHS-4) ${ }^{14}$ to provide state-level estimates of substance users and socioeconomic correlates of any substance use, as well as of three types of substance use (smoking, smokeless tobacco products, and alcohol consumption) individually among men aged between 15 and 54 years in NEI. The NFHS-4 is a cross-sectional and nationally representative survey that covered men aged 15-54 years in India's 29 states and all 7 union territories. The survey employed a two-stage sampling design in the rural and urban areas of each district of India to provide district level estimates. As part of the NFHS-4 601,509 households, 699,686 women, and 103,525 men from 28,583 primary sampling units composed of villages in rural areas and census enumeration blocks in the urban areas spread across 640 districts of India, were interviewed. The survey aimed at the male population covered a variety of information including demographic and socioeconomic characteristics, nutrition, contraception, fertility and fertility preferences, sexual behavior, attitudes towards gender roles and information pertaining to HIV/AIDS status.

One important part of the male schedule was the details of men's health and health-related behaviors. For the first time in the NFHS series, information on tobacco and alcohol consumption by eligible adult men and women were collected. Out of a total sample of 103,525 men aged between 15 and 54 years in India, a sample of 14,555 was drawn from the eight states from NEI viz. Arunachal Pradesh, Assam, Manipur, Meghalaya, Mizoram, Nagaland, Sikkim, and Tripura.

\subsection{Demographic and socioeconomic variables}

Following a literature review, we included some demographic and socioeconomic variables in our analysis. They were age, residence (urban/rural), education (no education, primary, secondary, and higher), caste $^{1}$ (Scheduled Castes (SCs), Scheduled Tribes (STs), Other Backward Classes (OBCs), and others), religion (Hindu, Muslim, Christian, and other), wealth index (poorest, poorer, middle, richer, and richest), mass media exposure in the form of listening radio, watching TV and reading newspapers (no, partial and full) and occupation (not

\footnotetext{
${ }^{1}$ The "caste system" is an Indian social stratification system which is used to represent the socio-economic status of an individual. The "caste" or "Jati" is hereditary and broadly divided into four groups for administrative reasons, namely, Scheduled Castes (SCs), Scheduled Tribes (STs), Other Backward Classes (OBCs), and General Castes (non-disadvantaged castes). For details, see Ref. 28.
}

working, professional, clerical/sales, agricultural services, skilled/unskilled).

\subsection{Substance consumption variables}

We analyzed four indicators of substance use among male adults aged between 15 and 54 years, viz. smoking tobacco, smokeless tobacco, consuming alcohol, and using any of these three substances.

\subsection{Tobacco (smoking and smokeless) consumption and frequency of consumption}

In terms of smoking tobacco, the following question was asked in the NFHS survey, "Do you currently smoke cigarettes/bidis?" The follow-up question for the frequency of smoking was, "In the last $24 \mathrm{~h}$, how many cigarettes/bidis did you smoke?" Answers were recorded using a response code of $0 \mathrm{~h}, 1 \mathrm{~h}, 1-2 \mathrm{~h}$, and more than $2 \mathrm{~h}$. Despite NFHS giving information on the frequency of cigarettes and bidi smoking separately, we combined the data together since we are investigating overall smoking behavior of male adults in NEI. For smokeless tobacco, the question posed was, "In what other form do you currently smoke or use tobacco?" Here responses included gutka/pan masala with tobacco, khaini, pan with tobacco. However, the frequency for smokeless tobacco was not collected in the survey.

\subsection{Alcohol consumption and its frequency}

To obtain information on alcohol consumption the following question was asked in the NFHS survey, "Do you drink alcohol?" with response options "Yes" and "No". This was followed by asking, "How often do you drink alcohol?" Responses were coded as: "almost every day", "about once a week", or "less than once a week".

\subsection{Outcome variables}

We considered four outcome variables for measuring substance use, viz. smoking, smokeless tobacco use, alcohol consumption, and using any of these substances. We re-coded all responses as dichotomous variables for logistic regression analysis.

\section{Methods}

We used sample descriptions and cross tabulation to examine the association between socioeconomic correlates and outcome variables. We assigned appropriate sample weights in the analysis. We used a chisquare test to examine the statistical significance of associations between outcome variables and each independent variable. Finally, we carried out a logistic regression analysis to investigate the socioeconomic correlates of substance consumption in the study area. Statistical significance was set at $\mathrm{P}<0.05$ for the study. All analyses were carried out using the statistical software package, STATA version 13.1.

\section{Results}

\subsection{Sample description}

The sample description is presented in Table 1 . The majority of respondents $(68.15 \%)$ came from rural areas. About $11.47 \%$ of the sample population had no education, $14.84 \%$ had a primary level education, $60.09 \%$ had a secondary level education (which represents the largest group in our sample), and about $13.60 \%$ had a higher level of education. About $39.40 \%$ were Hindus, $11.71 \%$ were Muslim, and $48.89 \%$ of the respondents belonged to other religions. By caste group, ST respondents represented more than half of the sample $(51.84 \%)$, followed by others (25.61\%), OBCs (14.69\%), and SCs (7.86\%). 
Table 1

Sample description of adults aged 15 to 54 in the states of Northeast India, 2015-2016.

\begin{tabular}{|c|c|c|}
\hline Background characteristics & Weighted (\%) & Frequency (n) \\
\hline \multicolumn{3}{|l|}{ Age groups } \\
\hline $15-19$ & 15.65 & 2278 \\
\hline $20-24$ & 13.54 & 1970 \\
\hline $25-29$ & 14.32 & 2084 \\
\hline $30-34$ & 13.5 & 1965 \\
\hline $35-39$ & 13.22 & 1924 \\
\hline $40-44$ & 11.35 & 1652 \\
\hline $45-49$ & 10.39 & 1512 \\
\hline $50-54$ & 8.05 & 1171 \\
\hline \multicolumn{3}{|l|}{ Place of residence } \\
\hline Urban & 31.85 & 4636 \\
\hline Rural & 68.15 & 9919 \\
\hline \multicolumn{3}{|l|}{ Educational level } \\
\hline No education & 11.47 & 1670 \\
\hline Primary & 14.84 & 2159 \\
\hline Secondary & 60.09 & 8746 \\
\hline Higher & 13.60 & 1980 \\
\hline \multicolumn{3}{|l|}{ Religion } \\
\hline Hindu & 39.40 & 5735 \\
\hline Muslim & 11.71 & 1705 \\
\hline Others & 48.89 & 7115 \\
\hline \multicolumn{3}{|l|}{ Caste group } \\
\hline Others & 25.61 & 3728 \\
\hline OBC & 14.69 & 2138 \\
\hline ST & 51.84 & 7545 \\
\hline SC & 7.86 & 1144 \\
\hline \multicolumn{3}{|l|}{ Wealth Index } \\
\hline Poorest & 12.10 & 1762 \\
\hline Poorer & 28.30 & 4119 \\
\hline Middle & 26.03 & 3789 \\
\hline Richer & 21.16 & 3081 \\
\hline Richest & 12.40 & 1805 \\
\hline \multicolumn{3}{|l|}{ Occupation } \\
\hline Not working & 22.94 & 3338 \\
\hline Professional & 5.55 & 808 \\
\hline Clerical/sales & 11.56 & 1683 \\
\hline Agricultural & 31.12 & 4530 \\
\hline Services & 8.95 & 1302 \\
\hline Skilled or unskilled & 19.88 & 2894 \\
\hline \multicolumn{3}{|l|}{ Radio } \\
\hline no at al & 67.25 & 9788 \\
\hline in a week & 25.61 & 3727 \\
\hline everyday & 7.14 & 1040 \\
\hline \multicolumn{3}{|l|}{ TV } \\
\hline No & 12.3 & 1790 \\
\hline Once in a week & 33.36 & 4856 \\
\hline Everyday & 54.34 & 7909 \\
\hline \multicolumn{3}{|l|}{ News paper } \\
\hline No & 42.02 & 6116 \\
\hline Once in a week & 38.21 & 5562 \\
\hline Everyday & 19.77 & 2877 \\
\hline \multicolumn{3}{|l|}{ States } \\
\hline Arunachal Pradesh & 14.7 & 2140 \\
\hline Assam & 28.79 & 4191 \\
\hline Manipur & 12.96 & 1886 \\
\hline Meghalaya & 8.49 & 1236 \\
\hline Mizoram & 12.02 & 1749 \\
\hline Nagaland & 10.97 & 1596 \\
\hline Sikkim & 6.04 & 879 \\
\hline Tripura & 6.03 & 878 \\
\hline
\end{tabular}

Source: Author's calculation from NFHS-4 data

According to the wealth index, $12.10 \%$ of respondents were classified as poorest, $28.30 \%$ as poorer, $26.03 \%$ as middle income, $21.16 \%$ as richer, and $12.40 \%$ represented the richest group. All states from NEI were included in our study sample. About $22.94 \%$ of the youth were not working at the time of the survey, $31.12 \%$ were working in the agricultural section and only $5.55 \%$ were in professional services.

\subsection{Prevalence and magnitude of substance use (smoking, smokeless tobacco product use, and alcohol consumption) in NEI states}

Panel A of Fig. 1 shows a comparison between the prevalence of substance use in NEI states with other Indian states and with national substance use figures. The prevalence of substance use in NEI states is markedly higher than the national average and that of other states (for example, any substance use in other states: $50.37 \%$ against NEI: 70.83\%; alcohol consumption in NEI: $46.74 \%$ vs. India: $29.51 \%$ ).

Secondly, there is a large variation across NEI states in all three indicators of substance consumption. Any substance consumption remains the highest in the state of Mizoram with (81.07\%), followed by Tripura (75.17\%). The figure was the lowest in Sikkim (60.86\%). While Meghalaya and Mizoram showed the highest prevalence of smoking, smokeless tobacco product usage is higher in Nagaland and Manipur. Within these states, alcohol consumption is the highest in Arunachal Pradesh and the lowest in Assam.

Table 2 presents the absolute number of substance users by states and by type of substance. There are about 10.2 million substance users in the NEI states, of which Assam's share is the highest (67.06 lakhs) because of population size. Assam is followed by Tripura (9.57 lakhs). States other than Assam and Sikkim contribute more substance users than their population share. Out of eight states, alcohol consumers represent the largest group of substance users in the five states. Other than Assam and Sikkim, the remaining states' share of substance users to total users is higher than their share of the total population in NEI.

\subsection{Frequency of substance use (smoking and alcohol consumption) in NEI}

The frequency of smoking and alcohol consumption are presented in Table 3. The frequency of smoking and alcohol consumption in the NEI is again much higher compared to the national average. The frequency of smoking and alcohol consumption also varies across NEI states. The consumption of six or more cigarettes (or bidis) in the last $24 \mathrm{~h}$ was found to be the highest in the state of Mizoram (57.79\%) followed by Meghalaya (45.84\%). Arunachal Pradesh, Assam, and Sikkim had the lowest percentage of adults who had smoked in the preceding $24 \mathrm{~h}$.

In contrast, the frequency of alcohol consumption almost every day is found to be the highest in the state of Assam (24.02\%) followed by Arunachal Pradesh (23.38\%). The state with the lowest reported alcohol consumption is Tripura (8.34\%), followed by Manipur (11.85\%) and Nagaland (12.27).

\subsection{Bivariate analysis}

Fig. 2 presents the age pattern of substance use among adults. It emerged that about $21.02 \%$ of adolescents consume alcohol, and this number doubles in the 20 to 24-year age group. Alcohol consumption appears to be the highest among 30 to 34 -year-olds, followed by a large plateau in the 35 to 49 -year age group. In the adolescent age group, consumption of smokeless tobacco products is the highest $(26.80 \%)$ of all types of substances used. The age pattern for smoking and the consumption of smokeless tobacco products are parallel, except in the 15 to 19 and 50 to 54 age groups. Both smokeless tobacco and alcohol consumption prevalence is reduced in the 45 to 54 -year age group. The use of any substance among adolescents is as high as $44.38 \%$, despite having the lowest prevalence among all groups. This rises to $71.02 \%$ in the 20-24 year age group and results in a large plateau (76.00\%-78.00\%) in the 20-49 year age group, before dipping down to $72.00 \%$ in the $50-54$ year age group.

Table 4 shows the prevalence of substance use among respondents by socioeconomic characteristics. There is no pronounced difference in substance use by rural-urban residents. Percent of smokers reduce when education level increases. In case of smokeless tobacco, the prevalence increases from "no education" to "primary education" and then drops continuously with increase in education of the respondents. Any type of 
A. India, other states, and Northeast states

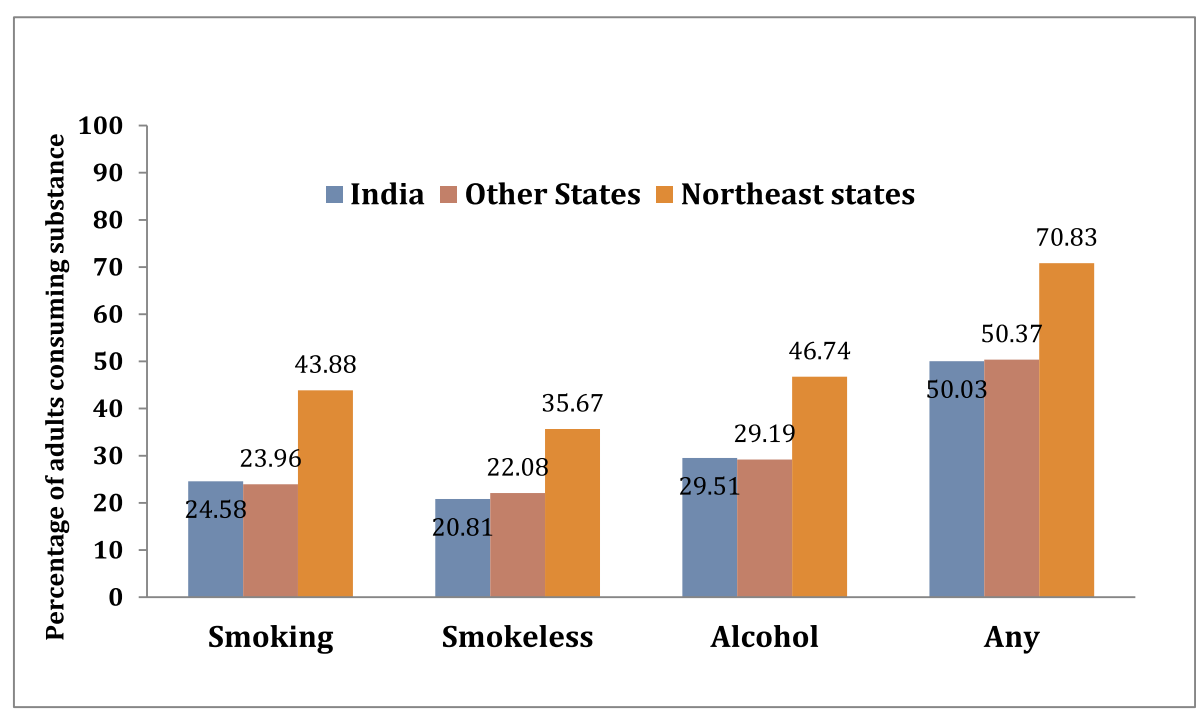

\section{B. NEI states}

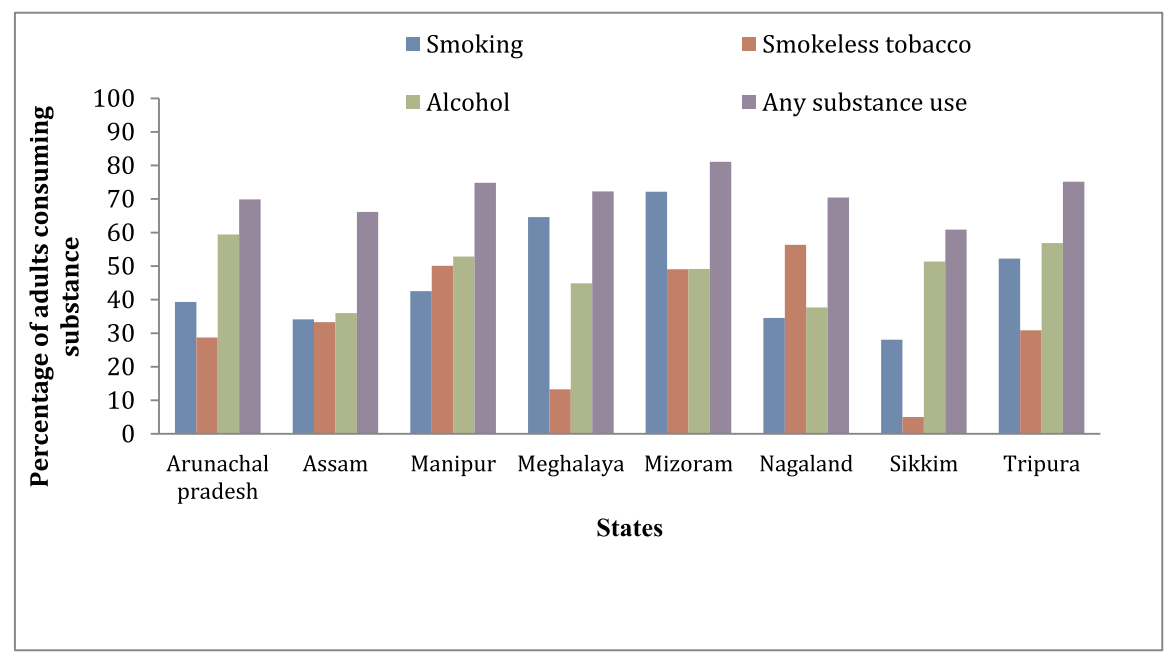

Fig. 1. Prevalence of substance use among adults aged 15 to 54 in India and in the states of Northeast India, 2015-2016.

Table 2

Absolute number of substance consumers (expressed in 100,000 or in lakhs) among males aged 15 to 54 in the states of Northeast India, 2015-2016.

\begin{tabular}{|c|c|c|c|c|c|c|}
\hline States & Total smokers & $\begin{array}{l}\text { Total smokeless tobacco } \\
\text { consumers }\end{array}$ & $\begin{array}{l}\text { Total alcohol } \\
\text { consumers }\end{array}$ & $\begin{array}{l}\text { Any substance } \\
\text { consumption }\end{array}$ & $\%$ share of population & $\begin{array}{l}\% \text { share of substance } \\
\text { consumers }\end{array}$ \\
\hline Arunachal Pradesh & 1.87 & 1.36 & 2.82 & 3.32 & 3.17 & 3.24 \\
\hline Assam & 34.60 & 33.76 & 36.51 & 67.06 & 67.77 & 65.53 \\
\hline Manipur & 4.16 & 4.89 & 5.17 & 7.32 & 6.54 & 7.15 \\
\hline Meghalaya & 5.89 & 1.19 & 4.02 & 6.59 & 6.10 & 6.44 \\
\hline Mizoram & 2.59 & 1.76 & 1.76 & 2.91 & 2.40 & 2.84 \\
\hline Nagaland & 2.05 & 3.34 & 2.24 & 4.18 & 3.97 & 4.09 \\
\hline Sikkim & 0.64 & 0.11 & 1.17 & 1.39 & 1.52 & 1.35 \\
\hline Tripura & 6.65 & 3.93 & 7.24 & 9.57 & 8.52 & 9.35 \\
\hline
\end{tabular}

Source: Author's calculation from NFHS-4 data and Census 2001 and 2011 data

substance use is reduced as education increases from primary to secondary or a higher level of education. An interesting pattern is observed for smokeless tobacco product consumption by wealth index. Unlike with smoking and alcohol consumption, the differential in smokeless tobacco product use by wealth index is neither sharp nor monotonically reducing. However, the consumption of any of these substances decreases with an increase in the level of wealth.

While the highest prevalence of smoking was found among people belonging to "other religions" (51.53\%), the consumption of smokeless tobacco products $(34.20 \%)$ and alcohol consumption (51.25\%) were found to be the highest among respondents belonging to Hindu religions. The prevalence of any substance consumption is the lowest among Muslim youths (57.68\%). Except for smokeless tobacco, all other types of substance prevalence are found to be the highest among the male belonging to OBCs. The prevalence of substance use is lower among males exposed to various types of media regularly. Similarly, 
Table 3

Frequency of smoking and alcohol consumption among adults aged 15 to 54 in India and in the states of Northeast India, 2015-2016.

\begin{tabular}{|c|c|c|c|c|c|c|}
\hline \multirow[t]{2}{*}{ States } & \multicolumn{3}{|c|}{$\begin{array}{l}\text { Number of cigarettes/bidis in last } \\
24 \mathrm{~h}\end{array}$} & \multicolumn{3}{|c|}{$\begin{array}{l}\text { Frequency of alcohol } \\
\text { consumption }\end{array}$} \\
\hline & $\begin{array}{l}0 \text { Bidis/ } \\
\text { cigarettes }\end{array}$ & $\begin{array}{l}\text { Between } 1 \\
\text { and } 5 \\
\text { bidis/ } \\
\text { cigarettes }\end{array}$ & 6 or more & $\begin{array}{l}\text { Almost } \\
\text { every } \\
\text { day }\end{array}$ & $\begin{array}{l}\text { About } \\
\text { once a } \\
\text { week }\end{array}$ & $\begin{array}{l}\text { Less } \\
\text { than } \\
\text { once a } \\
\text { week }\end{array}$ \\
\hline $\begin{array}{l}\text { Arunachal } \\
\text { Pradesh }\end{array}$ & 70.80 & 15.76 & 13.43 & 23.38 & 54.31 & 22.31 \\
\hline Assam & 69.07 & 16.93 & 13.99 & 24.02 & 51.3 & 24.68 \\
\hline Manipur & 62.38 & 28.16 & 9.46 & 11.85 & 40.89 & 47.26 \\
\hline Meghalaya & 42.40 & 11.76 & 45.84 & 18.48 & 43.17 & 38.35 \\
\hline Mizoram & 30.81 & 11.4 & 57.79 & 15.01 & 40.05 & 44.94 \\
\hline Nagaland & 68.02 & 11.03 & 20.95 & 12.27 & 41.35 & 46.38 \\
\hline Sikkim & 72.05 & 9.74 & 18.21 & 18.01 & 44.27 & 37.72 \\
\hline Tripura & 48.50 & 25.88 & 25.62 & 8.34 & 45.88 & 45.78 \\
\hline India & 75.95 & 20.1 & 3.95 & 12.41 & 40.55 & 47.04 \\
\hline
\end{tabular}

Source: Author's calculation from NFHS-4 data

males with professional occupation consume the least substance.

\subsection{Binary logistic regression analysis}

Binary logistic regression models were applied to investigate socioeconomic correlates of smoking, the consumption of smokeless tobacco products, alcohol consumption, and the use of any of these substances among male adults. The odds ratios (ORs) for each outcome variable (at 95\% confidence interval CI) are presented in Table 5. The results of the regression analysis indicate that the socioeconomic characteristics of male adults are significantly associated with their substance use behavior.

Age is positively associated with all types of substance use except smokeless tobacco $(p<0.001)$. After controlling for other socioeconomic characteristics, male adults residing in rural areas had lower odds for all three types of substance use (smoking OR: 0.85; 95\% CI: 0.77-0.92; smokeless tobacco products OR: 0.93 ; 95\% CI: $0.85-1.03$; alcohol OR: 093; 95\% CI:0.84-1.02). Male adults with a secondary or higher education had lower odds of smoking than the others. We found a similar negative association between education and alcohol consumption (statistically significant result only for secondary education, OR: 0.85 ; 95\% CI: 0.74-0.97). However, compared to males without education, males with a primary or secondary level education had a higher likelihood of consuming smokeless tobacco products (statistically significant result only for primary education, OR: $1.26 ; 95 \%$ CI:1.09-1.46).

While the probability of alcohol consumption is the lowest among Muslims (OR: 0.07; 95\% CI: 0.06-0.09), we do not observe any statistically significant association between religion and smoking or religion and smokeless tobacco. The odds of alcohol consumption is the highest among Hindus. Among social groups, males belonging to STs have a higher likelihood of smoking (OR: 1.54, 95\% CI: 1.35-1.76) and consuming alcohol (OR: 2.53 , 95\% CI: 2.20-2.90), compared to males from other groups. The likelihood of any substance consumption is the highest among tribal males (OR: 2.14, 95\% CI: 1.85-2.48) followed by males from SC groups (OR:1.34, CI:1.14-1.59).

The odds of smoking are reduced as the wealth index of households improve (for the richest wealth index for smoking OR: 0.66 ; $95 \% \mathrm{CI}$ : 0.54-0.80). The association between smokeless tobacco and wealth index is not statistically significant. The odds of alcohol consumption decrease from poorest to middle wealth index and then it rises again. The likelihood of using any substance use decreases with raising wealth index of the males.

The use of the substance is statistically significantly associated with the occupation of adult males. Males working as skilled or unskilled workers have the highest odds of consuming any substance use (OR:3.57, 95\% CI: 3.13-4.07). The adult males regularly exposed to television have higher of smoking, smokeless tobacco or any substance use. Exposure to radio is not statistically significantly associated with substance use. Male adults reading the newspaper regularly have lower odds of smoking (OR: 0.81, 95\% CI:0.71-0.93). After controlling for socioeconomic factors, the probability of smoking is the highest in Mizoram, followed by Meghalaya and Tripura. The odds of smokeless tobacco product consumption is the highest in Nagaland followed by Manipur and Mizoram. Similarly, the probability of alcohol consumption is the highest in Arunachal Pradesh followed by Manipur and Tripura. The likelihood of any substance consumption is the lowest in Sikkim and is the highest in Mizoram.

\section{Discussion and conclusion}

Previous studies found that NEI consistently bears a higher burden of premature mortality. ${ }^{15,16}$ The burden of non-communicable diseases like cancer, diabetes, and cardiovascular diseases in India has been growing at a faster rate in recent years including in the NEI states. ${ }^{17}$

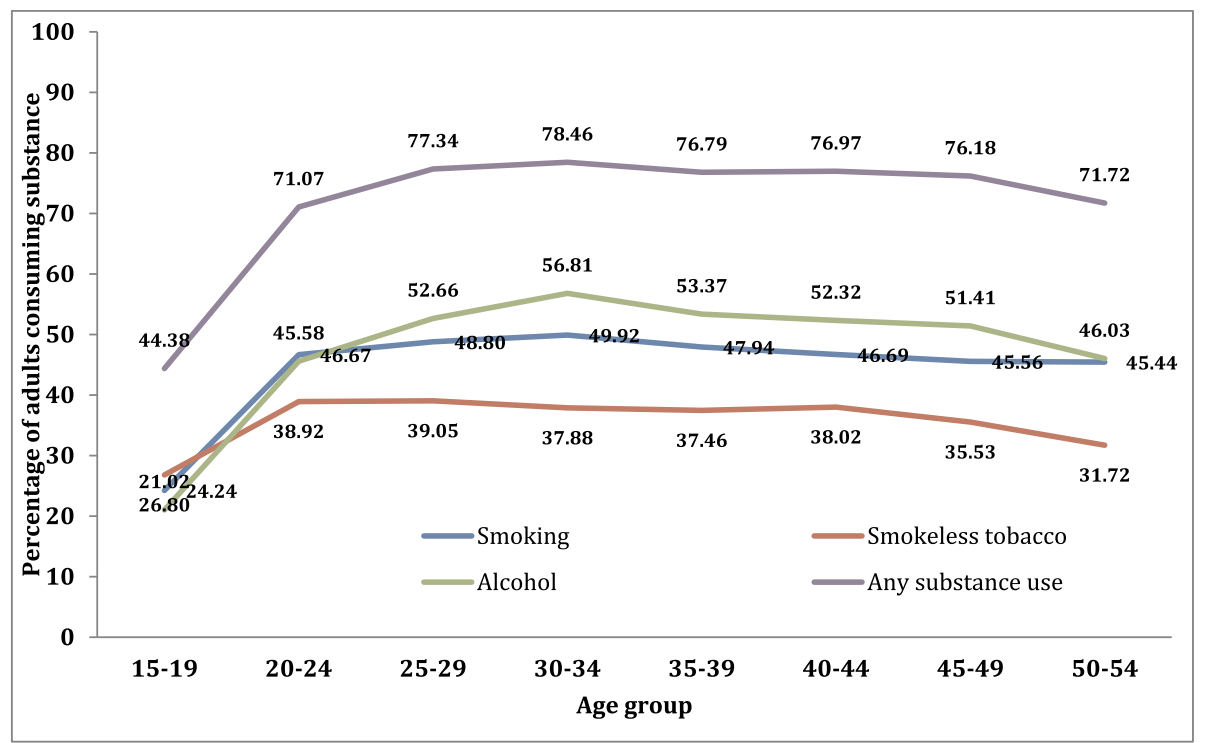

Fig. 2. Age pattern of substance consumption among adults aged 15 to 54 in the states of Northeast India, 2015-2016. 
Table 4

Bivariate analysis of substance consumption with background characteristics, the states of Northeast India, 2015-2016.

\begin{tabular}{|c|c|c|c|c|c|c|c|c|}
\hline Background characteristics & $\%$ of smokers & $\mathrm{P}$ value & $\begin{array}{l}\% \text { of smokeless tobacco } \\
\text { consumers }\end{array}$ & $\mathrm{p}$ value & $\%$ of alcohol consumers & $\mathrm{p}$ value & $\begin{array}{l}\% \text { of any substance } \\
\text { consumption }\end{array}$ & $\mathrm{p}$ value \\
\hline \multicolumn{9}{|l|}{ Place of residence } \\
\hline Urban & 39.97 & 0.096 & 35.12 & 0.000 & 39.50 & 0.208 & 66.47 & 0.826 \\
\hline Rural & 39.13 & & 32.54 & & 41.00 & & 67.95 & \\
\hline \multicolumn{9}{|l|}{ Educational level } \\
\hline No education & 50.10 & 0.000 & 30.50 & 0.000 & 43.27 & 0.000 & 76.42 & 0.000 \\
\hline Primary & 51.08 & & 38.13 & & 43.31 & & 77.45 & \\
\hline Secondary & 35.53 & & 33.31 & & 39.97 & & 64.54 & \\
\hline Higher & 29.09 & & 27.95 & & 37.40 & & 58.95 & \\
\hline \multicolumn{9}{|l|}{ Religion } \\
\hline Hindu & 35.57 & 0.000 & 34.20 & 0.000 & 51.25 & 0.000 & 69.68 & 0.000 \\
\hline Muslim & 40.29 & & 30.78 & & 4.87 & & 57.68 & \\
\hline Others & 51.53 & & 32.24 & & 49.72 & & 73.30 & \\
\hline \multicolumn{9}{|l|}{ Caste group } \\
\hline SC & 36.18 & 0.000 & 31.04 & 0.005 & 19.44 & 0.000 & 58.82 & 0.000 \\
\hline ST & 32.35 & & 36.79 & & 50.39 & & 69.00 & \\
\hline OBC & 49.02 & & 28.85 & & 59.95 & & 77.19 & \\
\hline Others & 41.20 & & 42.68 & & 47.21 & & 72.06 & \\
\hline \multicolumn{9}{|l|}{ Wealth index } \\
\hline Poorest & 45.67 & & 30.33 & & 47.72 & 0.000 & 75.10 & \\
\hline Poorer & 41.55 & & 33.57 & 0.116 & 39.87 & & 68.68 & \\
\hline Middle & 35.47 & & 34.28 & & 39.30 & & 65.79 & \\
\hline Richer & 36.89 & & 35.28 & & 39.21 & & 64.65 & \\
\hline Richest & 32.52 & & 29.52 & & 36.74 & & 59.29 & \\
\hline \multicolumn{9}{|l|}{ Occupation } \\
\hline Not working & 23.17 & 0.000 & 24.33 & 0.000 & 25.71 & 0.000 & 45.87 & 0.000 \\
\hline Professional & 30.65 & & 27.03 & & 33.54 & & 57.53 & \\
\hline Clerical/sales & 38.88 & & 36.21 & & 38.63 & & 69.15 & \\
\hline Agriculture & 44.33 & & 31.63 & & 44.00 & & 73.21 & \\
\hline Services & 41.15 & & 34.23 & & 43.25 & & 70.86 & \\
\hline Skilled/unskilled worker & 47.73 & & & & 50.70 & & 78.65 & \\
\hline \multicolumn{9}{|l|}{ Watching Television } \\
\hline No & 40.88 & & 32.02 & 0.000 & 35.14 & 0.031 & 69.89 & 0.000 \\
\hline Partial & 42.85 & 0.001 & 33.04 & & 41.57 & & 69.61 & \\
\hline Fully & 36.29 & & 33.46 & & 41.49 & & 65.54 & \\
\hline \multicolumn{9}{|l|}{ Listening radio } \\
\hline No & 38.17 & & 32.43 & & 40.07 & 0.000 & 67.63 & 0.850 \\
\hline Partial & 43.22 & 0.094 & 35.95 & & 43.29 & & 68.72 & \\
\hline Fully & 37.15 & & 29.38 & & 36.81 & & 62.41 & \\
\hline \multicolumn{9}{|l|}{ Reading newspaper } \\
\hline No & 43.14 & & 33.91 & 0.000 & 42.44 & & 71.88 & 0.000 \\
\hline Partial & 36.92 & 0.000 & 33.73 & & 39.99 & & 65.59 & \\
\hline Fully & 32.81 & & 29.04 & & 36.61 & & 58.89 & \\
\hline \multicolumn{9}{|l|}{ NE States } \\
\hline Arunachal Pradesh & 39.36 & & 29.82 & & 59.41 & 0.000 & 70.11 & 0.000 \\
\hline Assam & 34.41 & & 33.59 & & 36.02 & & 65.28 & \\
\hline Manipur & 42.64 & & 49.39 & & 52.83 & & 74.89 & \\
\hline Meghalaya & 65.33 & & 15.42 & & 44.88 & & 73.01 & \\
\hline Mizoram & 72.28 & & 43.77 & & 49.18 & & 82.73 & \\
\hline Nagaland & 34.58 & & 54.77 & & 37.7 & & 69.14 & \\
\hline Sikkim & 28.08 & & 5.38 & & 51.36 & & 59.09 & \\
\hline Tripura & 51.87 & & 28.56 & & 56.84 & & 73.86 & \\
\hline
\end{tabular}

Note: $\mathrm{p}$ value indicates the $\mathrm{p}$ value of chi square test of association.

Source: Author's calculation from NFHS-4 data

Although, various reports highlighted the presence of a higher prevalence of substance use in the NEI states, empirical analyses on substance use and its risk factors in the region are lacking in public health literature. Because of dissimilar geography, history, culture, and ethnic diversity, the magnitude and disparity in substance use behavior by various socioeconomic groups in the NEI states may also be different from that in the rest of the country. Our aim was to investigate how the socioeconomic conditions in which young adults were living, relates to their substance use. Understanding this relationship, especially in an area where substance use is relatively high, is an important step towards identifying individuals at risk. With this purpose, we investigated differential substance consumption behavior across states and population sub-groups in NEI using data from a recent representative survey. Our study produced a few interesting findings on substance use which are important for policy discourse.
First, we found that the use of any or specific kinds of substances is substantially higher among male adolecents and adults from NEI states compared to the rest of India. Among the three types of substance use examined, alcohol consumption is the highest, followed by smoking and the use of smokeless tobacco products. Male youth from NEI also consume these substances more frequently than their counterparts in other parts of the country. Out of 10.2 million substance consumers, more than $65 \%$ live in the state of Assam. There is wide variation in the prevalence and intensity of substance use across the states. Interestingly, the prevalence of smoking in NEI is far higher than that observed in some western countries. ${ }^{18,19}$ Our findings are consistent with previous studies conducted in small geographic regions of NEI. ${ }^{9,20,21,22}$ Here it is worth noting that the prevalence of tobacco use (both smoking and in the form of smokeless products) among adolescents from NEI is considerably higher than in other countries. ${ }^{23} \mathrm{~A}$ high 
Table 5

Binary logistic regression analysis of substance consumption with background characteristics in the states of Northeast India, 2015-2016.

\begin{tabular}{|c|c|c|c|c|c|c|c|c|c|c|c|c|c|c|c|c|}
\hline \multirow{3}{*}{$\begin{array}{l}\text { Background characteristics } \\
\text { Age }\end{array}$} & \multirow{3}{*}{$\begin{array}{l}\text { Odds Ratio } \\
\text { Smoking } \\
1.05\end{array}$} & \multirow{3}{*}{$\begin{array}{l}\text { P value } \\
0.000\end{array}$} & \multicolumn{2}{|c|}{$(95 \% \mathrm{CI})$} & \multirow{3}{*}{$\begin{array}{l}\text { Odds Ratio } \\
\text { Smokeless to } \\
1.00\end{array}$} & \multirow{3}{*}{$\begin{array}{l}\text { P value } \\
\text { bacco } \\
0.797\end{array}$} & \multicolumn{2}{|c|}{$(95 \% \mathrm{CI})$} & \multirow{3}{*}{$\begin{array}{l}\text { Odds Ratio } \\
\text { Alcohol } \\
1.07\end{array}$} & \multirow{3}{*}{$\begin{array}{l}\text { P value } \\
0.000\end{array}$} & \multicolumn{2}{|c|}{$(95 \% \mathrm{CI})$} & \multirow{3}{*}{$\begin{array}{l}\text { Odds Ratio } \\
\text { Any Substar } \\
1.10\end{array}$} & \multirow{3}{*}{$\begin{array}{l}P \text { value } \\
0.000\end{array}$} & \multicolumn{2}{|c|}{$(95 \% \mathrm{CI})$} \\
\hline & & & & & & & & & & & & & & & & \\
\hline & & & 1.03 & 1.07 & & & 0.98 & 1.02 & & & 1.05 & 1.09 & & & 1.08 & 1.12 \\
\hline \multicolumn{17}{|l|}{ Place of residence } \\
\hline $\begin{array}{l}\text { Rural } \\
\text { Educational level } \\
\text { No education }\end{array}$ & 0.85 & 0.001 & 0.77 & 0.94 & 0.93 & 0.164 & 0.85 & 1.03 & 0.93 & 0.111 & 0.84 & 1.02 & 0.89 & 0.020 & 0.80 & 0.98 \\
\hline Primary & 1.09 & 0.220 & 0.95 & 1.25 & 1.26 & 0.002 & 1.09 & 1.46 & 0.97 & 0.668 & 0.84 & 1.12 & 1.21 & 0.018 & 1.03 & 1.42 \\
\hline Secondary & 0.83 & 0.004 & 0.73 & 0.94 & 1.08 & 0.291 & 0.94 & 1.23 & 0.85 & 0.016 & 0.74 & 0.97 & 0.89 & 0.109 & 0.77 & 1.03 \\
\hline Higher & 0.69 & 0.000 & 0.58 & 0.83 & 1.06 & 0.559 & 0.88 & 1.27 & 1.01 & 0.955 & 0.84 & 1.20 & 0.99 & 0.932 & 0.82 & 1.20 \\
\hline Religion & & & & & & & & & & & & & & & & \\
\hline Hindu & & & & & & & & & & & & & & & & \\
\hline Muslim & 1.09 & 0.237 & 0.94 & 1.26 & 1.02 & 0.739 & 0.89 & 1.18 & 0.08 & 0.000 & 0.07 & 0.10 & 0.63 & 0.000 & 0.55 & 0.73 \\
\hline Others & 1.04 & 0.492 & 0.92 & 1.18 & 1.03 & 0.709 & 0.90 & 1.17 & 0.54 & 0.000 & 0.47 & 0.61 & 0.71 & 0.000 & 0.62 & 0.81 \\
\hline Caste group & & & & & & & & & & & & & & & & \\
\hline Others & & & & & & & & & & & & & & & & \\
\hline OBC & 0.91 & 0.180 & 0.80 & 1.04 & 1.22 & 0.004 & 1.07 & 1.39 & 1.37 & 0.000 & 1.20 & 1.56 & 1.18 & 0.015 & 1.03 & 1.35 \\
\hline ST & 1.54 & 0.000 & 1.35 & 1.76 & 1.05 & 0.464 & 0.92 & 1.21 & 2.53 & 0.000 & 2.20 & 2.90 & 2.14 & 0.000 & 1.85 & 2.48 \\
\hline SC & 1.25 & 0.004 & 1.07 & 1.46 & 1.30 & 0.001 & 1.11 & 1.52 & 1.29 & 0.002 & 1.10 & 1.50 & 1.34 & 0.001 & 1.14 & 1.59 \\
\hline Wealth index & & & & & & & & & & & & & & & & \\
\hline Poorest & & & & & & & & & & & & & & & & \\
\hline Poorer & 0.85 & 0.009 & 0.76 & 0.96 & 1.06 & 0.360 & 0.94 & 1.20 & 0.75 & 0.000 & 0.66 & 0.85 & 0.85 & 0.023 & 0.75 & 0.98 \\
\hline Middle & 0.77 & 0.000 & 0.68 & 0.89 & 1.05 & 0.499 & 0.91 & 1.21 & 0.66 & 0.000 & 0.58 & 0.76 & 0.76 & 0.000 & 0.65 & 0.88 \\
\hline Richer & 0.78 & 0.002 & 0.67 & 0.91 & 1.14 & 0.104 & 0.97 & 1.34 & 0.70 & 0.000 & 0.60 & 0.83 & 0.78 & 0.004 & 0.65 & 0.92 \\
\hline Richest & 0.66 & 0.000 & 0.54 & 0.80 & 1.00 & 0.998 & 0.82 & 1.21 & 0.71 & 0.000 & 0.58 & 0.86 & 0.67 & 0.000 & 0.55 & 0.82 \\
\hline Occupation & & & & & & & & & & & & & & & & \\
\hline Not working & & & & & & & & & & & & & & & & \\
\hline Profession & 1.32 & 0.004 & 1.09 & 1.60 & 1.15 & 0.164 & 0.95 & 1.39 & 1.34 & 0.002 & 1.12 & 1.61 & 1.39 & 0.000 & 1.16 & 1.67 \\
\hline Clerical/Sales & 1.96 & 0.000 & 1.71 & 2.26 & 1.53 & 0.000 & 1.33 & 1.77 & 1.91 & 0.000 & 1.66 & 2.20 & 2.31 & 0.000 & 2.00 & 2.67 \\
\hline Agriculture & 1.94 & 0.000 & 1.74 & 2.18 & 1.36 & 0.000 & 1.21 & 1.52 & 2.00 & 0.000 & 1.79 & 2.24 & 2.27 & 0.000 & 2.02 & 2.54 \\
\hline Services & 2.07 & 0.000 & 1.78 & 2.40 & 1.39 & 0.000 & 1.20 & 1.62 & 1.98 & 0.000 & 1.71 & 2.30 & 2.18 & 0.000 & 1.87 & 2.54 \\
\hline Skilled or unskilled workers & 2.68 & 0.000 & 2.37 & 3.02 & 2.10 & 0.000 & 1.86 & 2.38 & 3.11 & 0.000 & 2.76 & 3.52 & 3.57 & 0.000 & 3.13 & 4.07 \\
\hline Watching Television & & & & & & & & & & & & & & & & \\
\hline No & & & & & & & & & & & & & & & & \\
\hline Partial & 1.27 & 0.000 & 1.13 & 1.43 & 1.32 & 0.000 & 1.16 & 1.49 & 1.30 & 0.000 & 1.15 & 1.48 & 1.41 & 0.000 & 1.24 & 1.60 \\
\hline Fully & 1.20 & 0.005 & 1.06 & 1.36 & 1.34 & 0.000 & 1.17 & 1.53 & 1.17 & 0.018 & 1.03 & 1.34 & 1.27 & 0.001 & 1.11 & 1.45 \\
\hline Listening radio & & & & & & & & & & & & & & & & \\
\hline No & & & & & & & & & & & & & & & & \\
\hline Partial & 1.07 & 0.176 & 0.97 & 1.17 & 1.06 & 0.252 & 0.96 & 1.16 & 0.98 & 0.725 & 0.90 & 1.08 & 0.92 & 0.111 & 0.83 & 1.02 \\
\hline Fully & 1.03 & 0.680 & 0.88 & 1.21 & 1.04 & 0.621 & 0.89 & 1.22 & 0.91 & 0.216 & 0.77 & 1.06 & 0.93 & 0.404 & 0.79 & 1.10 \\
\hline Reading newspaper & & & & & & & & & & & & & & & & \\
\hline No & & & & & & & & & & & & & & & & \\
\hline Partial & 0.93 & 0.136 & 0.85 & 1.02 & 1.10 & 0.061 & 1.00 & 1.21 & 1.07 & 0.189 & 0.97 & 1.17 & 1.04 & 0.424 & 0.94 & 1.15 \\
\hline Fully & 0.81 & 0.002 & 0.71 & 0.93 & 0.95 & 0.434 & 0.83 & 1.09 & 1.00 & 0.996 & 0.87 & 1.14 & 0.90 & 0.155 & 0.78 & 1.04 \\
\hline NE States & & & & & & & & & & & & & & & & \\
\hline Arunachal Pradesh & & & & & & & & & & & & & & & & \\
\hline Assam & 0.91 & 0.155 & 0.79 & 1.04 & 1.06 & 0.424 & 0.92 & 1.22 & 0.51 & 0.000 & 0.44 & 0.58 & 0.91 & 0.225 & 0.79 & 1.06 \\
\hline Manipur & 1.44 & 0.000 & 1.24 & 1.69 & 2.10 & 0.000 & 1.79 & 2.46 & 0.92 & 0.299 & 0.79 & 1.08 & 1.63 & 0.000 & 1.37 & 1.93 \\
\hline Meghalaya & 2.99 & 0.000 & 2.56 & 3.50 & 0.33 & 0.000 & 0.27 & 0.40 & 0.49 & 0.000 & 0.42 & 0.58 & 1.07 & 0.403 & 0.91 & 1.27 \\
\hline Mizoram & 3.82 & 0.000 & 3.27 & 4.46 & 2.00 & 0.000 & 1.72 & 2.33 & 0.47 & 0.000 & 0.40 & 0.54 & 1.67 & 0.000 & 1.41 & 1.99 \\
\hline Nagaland & 0.77 & 0.000 & 0.67 & 0.89 & 3.10 & 0.000 & 2.68 & 3.57 & 0.37 & 0.000 & 0.32 & 0.43 & 0.95 & 0.500 & 0.81 & 1.11 \\
\hline Sikkim & 0.65 & 0.000 & 0.54 & 0.78 & 0.11 & 0.000 & 0.08 & 0.15 & 0.77 & 0.003 & 0.65 & 0.92 & 0.67 & 0.000 & 0.56 & 0.80 \\
\hline Tripura & 2.03 & 0.000 & 1.69 & 2.43 & 0.88 & 0.176 & 0.72 & 1.06 & 0.82 & 0.042 & 0.68 & 0.99 & 1.24 & 0.038 & 1.01 & 1.53 \\
\hline
\end{tabular}

Notes: OR= Odds Ratio; $\mathrm{p}<0.05, \mathrm{p}<0.01, \mathrm{p}<0.001$.

Source: Author's calculation from NFHS-4 data

level of substance use in NEI may be linked to the consumption of ricebased alcoholic drinks during religious and social functions and a consequent lack of social inhibitions towards substance use. ${ }^{10}$ It may be also be attributed to easy access to and availability of substances due to geographical location and state policy.

Secondly, from our study, we can deduce that the problem of smoking and drinking alcohol is more prevalent among underprivileged people in the NEI states. The results show that social groups belonging to STs have the highest probability of smoking and alcohol consumption. National Family Health Survey-2, shows that tobacco use was significantly higher among SC and ST populations. On the other hand, except for in the case of smokeless tobacco products, education appears to be a reducing factor for substance use. Similarly, the wealth status of male youth is negatively associated with smoking and drinking alcohol.
The socioeconomic pattern of substance consumption among male youths in NEI states is similar to that found in national level studies ${ }^{24,25}$ and in other low and middle income-countries. ${ }^{26}$ Interestingly, we do not find a statistically significant association between educational status or wealth index status with consumption of smokeless tobacco. We also found that males working as a skilled or unskilled worker have more than 3 times of odd of any substance consumption.

Our results further demonstrate that despite the very high prevalence of substance use in all north-eastern states, there is significant variation in the level and pattern of substance use within the states of NEI. While male adults from Mizoram exhibit the highest level of smoking, the likelihood of smokeless tobacco is the highest among male adults from Nagaland. At the same time, the prevalence of alcohol use is the lowest in the state of Assam, yet the frequency of consumption is the 
highest. Therefore, our findings indicate that state-specific policy intervention is needed to reduce the burden of substance use among various states of NEI.

This study has certain limitations. First, we lacked sufficient information to disaggregate the large heterogeneous groups of the "scheduled tribes" or the "other backward classes". Because the NEI population varies considerably by ethnic origin and therefore in their cultural practices, we may assume that our study underestimates the extent of prevailing differences among ethnic groups. For example, a previous study found that the proportion of tobacco users among tea garden workers were about $85 \%$ compared to $42 \%$ users among the general population. ${ }^{27}$ Secondly, we assumed that the respondents were reporting their consumption of tobacco or alcohol honestly and that their reporting was not affected by their socioeconomic status or cultural setting. In practice, self-reported information on substance consumption may be different from data obtained through clinical trials. Thirdly, the association between substance use and socioeconomic characteristics cannot indicate any causal relationship between them because of the cross-sectional nature of NFHS data.

The findings of this study can be used as a crucial input for the cessation of substance use in the study area. The prevalence of substance use in NEI is higher compared to both the national usage rates in India and the global average. This underscores the importance of recognizing substance use as a public health menace in NEI. Since the burden of substance use is higher among the socio-economically disadvantaged male adults, government or non-governmental cessation program should target interventions accordingly. Specifically, this includes males who belong to households in the poorest wealth quintile, SC or ST population subgroups, working as skilled and non-skilled workers and living in rural NEI. By inaugurating the National Tobacco Control Program in 2007-2008, the government of India has been attempting to reduce the prevalence of tobacco use by raising awareness and by facilitating tobacco control laws. However, this program should be expanded effectively at grassroots level in the NEI. Health education programs, media messages, and other interventions need to be directed not only at discouraging smoking and drinking alcohol, but also towards creating awareness of the equally harmful, yet socially accepted consumption of smokeless tobacco products. These programs should be an integral part of India's National Health Program. At the same time, the imposition of a high tax on substance products can help reduce the consumption of those. Given that we also find substance consumption is high even among adolescents aged 15-19, a strict ban on accessing and consuming these items in public places may be needed to reduce the consumption among youth. However, the responsibility for the execution of a public program to curb the burden of substance use does not only rest on the shoulders of the government alone - but the success of such a program will also depend on community involvement. Effective substance control strategies need to be based on an intersectional approach with various ministries, health departments, gram panchayats, public health institutions, and civil society groups. As a previous study in NEI finds, parental substance consumption associated with that of offspring's, program to reduce substance consumption should target the parents of adolescent youths. At the same time, government and civil society should place greater emphasis on alternative entertainment such as sports, music or other creative work among male youths of NEI. Our study showed that the relatively poor and less educated use more substances, which may have a comparatively larger negative impact on their health due to a lack of awareness and access to better health facilities. It is, therefore, all the more critical to adopt policies that specifically address substance use among these sub-populations.

\section{Availability of data and materials}

We used publicly available secondary survey data obtained from the National Family Health Survey-2015-2016. The NFHS data supporting the findings of this study is available in the public domain for download (https://dhsprogram.com/data/available-datasets.cfm). The NFHS followed ethical clearance guidelines and norms. No separate ethics statement and consent for publication was required for this study.

\section{Ethics statement and consent to participate}

Not applicable.

\section{Consent for publication}

Not applicable.

\section{Conflicts of interest}

None.

\section{Funding}

No funding of any kind was granted for carrying out this study.

\section{Authors' contribution}

NS and BD conceptualized the study and analyzed the data. NS interpreted the results. NS wrote the final draft. Both the authors read and approved the final draft.

\section{Acknowledgements}

Not applicable.

\section{Appendix A. Supplementary data}

Supplementary data to this article can be found online at https:// doi.org/10.1016/j.cegh.2019.06.004.

\section{References}

1. Kumar V, Talwar R, Roy N, Raut D, Singh S. Psychosocial determinants of tobacco use among school going adolescents in Delhi, India. J Addict. 2014;2014.

2. Nyhlén A, Fridell M, Bäckström M, Hesse M, Krantz P. Substance abuse and psychiatric co-morbidity as predictors of premature mortality in Swedish drug abusers a prospective longitudinal study 1970-2006. BMC Psychiatry. 2011;11(1):122.

3. McGill V, Kowal-Vern A, Fisher SG, Kahn S, Gamelli R. The impact of substance use on mortality and morbidity from thermal injury. J Trauma Acute Care Surg. 1995;38(6):931-934.

4. Lal PG, Wilson NC, Gupta PC. Attributable deaths from smoking in the last 100 years in India. Curr Sci. 2012;103(9):1085-1090

5. Gajalakshmi V, Peto R, Kanaka TS, Jha P. Smoking and mortality from tuberculosis and other diseases in India: retrospective study of 43000 adult male deaths and 35 000 controls. The Lancet. 2003;362(9383):507-515.

6. Banjare P, Pradhan J. Socio-economic inequalities in the prevalence of multi-mor bidity among the rural elderly in Bargarh District of Odisha (India). PLoS One. 2014;9(6):e97832

7. Pandey A, Patni N, Sarangi S, et al. Association of exclusive smokeless tobacco consumption with hypertension in an adult male rural population of India. Tob Induc Dis. 2009;5(1):15.

8. Murthy P, Manjunatha N, Subodh BN, Chand PK, Benegal V. Substance use and addiction research in India. Indian J Psychiatr. 2010;52(Suppl1):S189.

9. Medhi GK, Hazarika NC, Mahanta J. Correlates of alcohol consumption and tobacco use among tea industry workers of Assam. Subst Use Misuse. 2006;41(5):691-706.

10. Mahanta B, Mohapatra PK, Phukan N, Mahanta J. Alcohol use among school-going adolescent boys and girls in an industrial town of Assam, India. Indian J Psychiatr. 2016;58(2):157.

11. Ladusingh L, Dhillon P, Narzary PK. Why do the youths in Northeast India use tobacco? J Environ Publ Health. 2017;2017.

12. IIPS (International Institute for Population Sciences). Global Adult Tobacco Survey India 2009-2010. Mumbai: IIPS; 2010.

13. TISS (Tata Institute of Social Sciences) Mumbai, MoHFW (Ministry of Health and Family Welfare), Government of India. Global Adult Tobacco Survey GATS 2 India 2016-17. 2018; 2018 Available at http://www.tiss.edu/view/6/mumbai-campus/ school-of-health-systems-studies/global-adult-tobacco-survey-2-india-2016-17/ outcomespublications-3/, Accessed date: 31 January 2019.

14. IIPS (International Institute for Population Sciences), ICF. National Family Health Survey (NFHS-4), 2015-16: India. Mumbai: IIPS; 2017. 
15. Saikia N, Singh A, Ram F. Adult male mortality in India: an application of the widowhood method. Asian Popul Stud. 2013;9(3):244-263.

16. Ram U, Jha P, Gerland P, et al. Age-specific and sex-specific adult mortality risk in India in 2014: analysis of 0. 27 million nationally surveyed deaths and demographic estimates from 597 districts. Lancet Glob Health. 2015;3(12):e767-e775.

17. ICMR, PHFI, IHME. India: Health of the Nation's States the India State-Level Disease Burden Initiative. 2017; 2017 Available at https://www.healthdata.org/sites/default/ files/files/policy_report/2017/India_Health_of_the_Nation\%27s_States_Report_2017. pdf, Accessed date: 3 September 2018.

18. Eurostat. Tobacco Consumption Statistics. 2014; 2014 Available at https://ec.europa. eu/eurostat/statistics-explained/index.php/Tobacco_consumption_statistics, Accessed date: 18 February 2019.

19. Lampert T, Lippe EVD, Müters S. Prevalence of Smoking in the Adult Population of Germany. 2013; 2013 Available at https://edoc.rki.de/handle/176904/1544, Accessed date: 31 January 2019.

20. Hazarika NC, Biswas D, Phukan RK, Hazarika D, Mahanta J. Prevalence and pattern of substance abuse at Bandardewa, a border area of Assam and Arunachal Pradesh. Indian J Psychiatr. 2000;42(3):262.

21. Kermode M, Songput CH, Sono CZ, Jamir TN, Devine A. Meeting the needs of women who use drugs and alcohol in North-east India-a challenge for HIV prevention services. BMC Public Health. 2012;12(1):825.
22. Chaturvedi HK, Mahanta J, Bajpai RC, Pandey A. Correlates of opium use: retrospective analysis of a survey of tribal communities in Arunachal Pradesh, India. BMC Public Health. 2013;13(1):325.

23. Asma S, Mackay J, Song SY, Zhao L, Morton J, et al. The GATS Atlas. Atlanta, GA: CDC Foundation; 20152015 [ accessed on October 11, 2018]. Available at. http:// www.cdc.gov/tobacco/global/gtss/tobacco_atlas/.

24. Kumar K, Kumar S, Singh AK. Prevalence and socio-demographic correlates of alcohol consumption: survey findings from five states in India. Drug Alcohol Depend. 2018;185:381-390

25. Rani M, Bonu S, Jha P, Nguyen SN, Jamjoum L. Tobacco use in India: prevalence and predictors of smoking and chewing in a national cross sectional household survey. Tobac Contr. 2003;12(4) e4-e4.

26. Hosseinpoor AR, Parker LA, d'Espaignet ET, Chatterji S. Social determinants of smoking in low-and middle-income countries: results from the World Health Survey. PLoS One. 2011;6(5):e20331.

27. Mahanta TG, Joshi R, Mahanta BN, Xavier D. Prevalence of modifiable cardiovascular risk factors among tea garden and general population in Dibrugarh, Assam, India. J Epidemiol Glob Health. 2013;3(3):147-156.

28. Dommaraju P, Agadjanian V, Yabiku S. The pervasive and persistent influence of caste on child mortality in India. Popul Res Pol Rev. 2008;27(4):477-495. 